\title{
Assessment Of Premenstrual Syndrome In Medical Students And Its Association With Progression Of Academic Years
}

\author{
Sadia Suboohi, Saba Pario, Ghazala Nasim, Sughra Abbasi, Shahanaz Hassan Siddiqui
}

ABSTRACT

Objectives: The objective was to determine the frequency of Premenstrual Syndrome and its association with progression of academic years among the medical students.

Study Design and Setting: A cross sectional study was conducted at United Medical and Dental College Karachi from January to June 2018 among 150 female medical students.

Methodology: A structured questionnaire was designed to assess the demographic characteristics and symptoms of PMS if any experienced by the participants included in the study. The severity symptoms of PMS were marked by the participants on the behalf of their impact on their routine activity \& performance, ranking from mild, moderate to severe. Data was analyzed using SPSS version 20.

Results: The frequency of PMS was reported as 39\% in the study participants among them $79.31 \%$ showed mild form, $17.24 \%$ showed moderate and $3.44 \%$ were diagnosed with severe PMS. Increased frequency of PMS in female medical students was observed to be associated with progression of their academic years, with final year students having highest percentage. Academic year of MBBS, type of accommodation, and occupation of mother, menstrual cycle regularity and history of PMS in family were found to be statistically significant risk factors associated with PMS.

Conclusion: Premenstrual syndrome is a prevalent health issue in medical students, increasing year to year during their studies, which may unfavorably have affects on their quality of life and overall performance.

Keywords: Menstrual cycle, Medical students, Premenstrual syndrome,

\section{INTRODUCTION:}

Premenstrual syndrome (PMS) is a recurrent occurrence of cyclical somatic or psychological symptoms or both, that occur before onset of menstrual cycle that is in luteal phase and resolve in follicular phase, at least by end of menstruation. This disorder is not caused by any organic disease. ${ }^{1}$ According to ACOG criteria, one of the following affective symptoms (depression, angry outbursts, irritability, anxiety, confusion, and social withdrawal) and any one of somatic symptoms (breast tenderness, abdominal bloating, headache, and

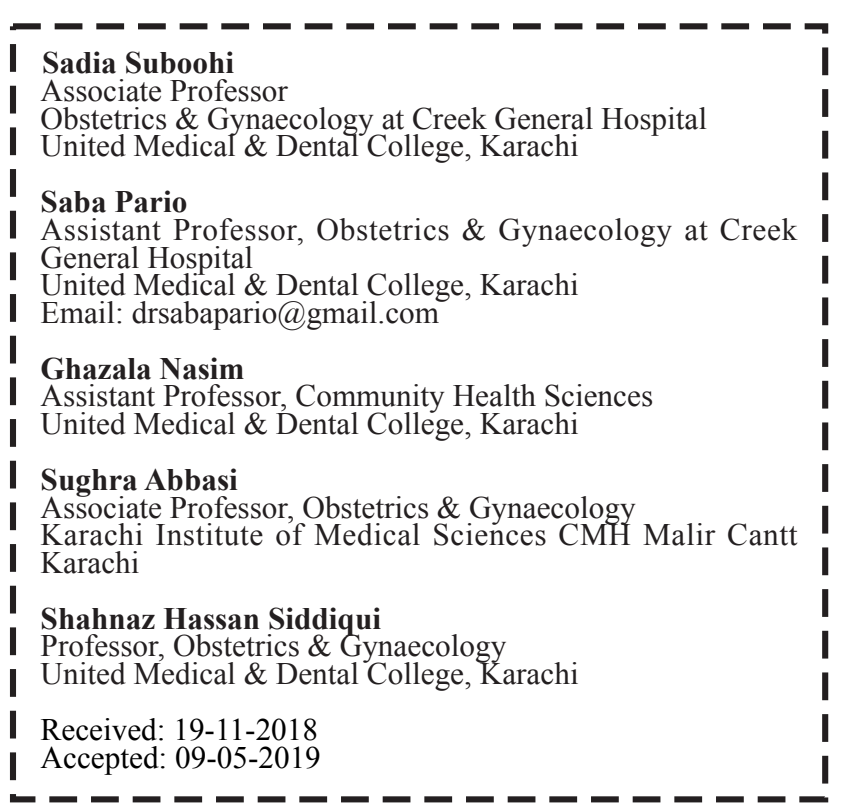

swelling of extremities) with an adverse impact on daily life activities, markedly affecting interpersonal relationships are required for diagnosis of Premenstrual syndrome. These cluster of symptoms should be present five days before start of periods in three previous cycles and settled by four days after onset of menstrual bleeding. ${ }^{2,3}$ Premenstrual dysphoric disorder or severe PMS is the extreme, predominantly psychological end of PMS. ${ }^{4}$

In literature spectrum of symptoms has been described but actually timing and severity are of most importance to any specific pattern of symptoms. ${ }^{5}$ PMS occur in four in ten women of reproductive age and 5-8\% of these experience were of severe form. ${ }^{6}$ PMS can cause significant morbidity adversely affecting interpersonal relationships, impairment of normal day to day functioning, negative impact on work performance and general well being and health of women .$^{7,8} \mathrm{PMS}$ is experienced by reproductive aged women, more prevalent in the younger age group leading to a significant public health problem in young girls. ${ }^{9}$ There have been many theories of aetiology but current evidence suggest that PMS is caused by abnormality of neurotransmitter function mainly serotonergic dysfunction, reinforced by verification that selective serotonin reuptake inhibitors reduce PMS symptoms. Others suggest that women suffering from PMS are 'sensitive' to progesterone and progestogens. ${ }^{10}$

Premenstrual syndrome must be differentiated from Premenstrual magnification, that may be due to underlying psychiatric or medical disorder in which symptoms are present all the time but exacerbated in premenstrual 
phase. ${ }^{11}$ According to research women diagnosed with PMS may have a devastating effect on herself, her family and colleagues around her. ${ }^{12}$ Management of PMS should be individualized, suggested treatment options are life style modification, hormonal medications, SSRI, cognitive behavioral therapies and total abdominal hystrectomy and bilateral oophrectomy as last resort in most refractory and failed cases. ${ }^{13}$ Majority of students in medical undergraduate studies are females in our country, high prevalence of PMS among them may affect their performance if left undiagnosed and untreated. Therefore the primary aim of this study was to assess the frequency of PMS, association of increase in frequency of PMS with progression of academic years and to study the factors associated with PMS among female medical students of United Medical and Dental College Karachi.

\section{METHODOLOGY:}

A cross sectional study was conducted to determine the frequency of PMS and factors associated with PMS among medical students of United Medical and Dental College, Karachi from January to June 2018 by convenient sampling on one hundred and fifty female medical students .Brief information about PMS was given to the participants, before conducting the study. Eligible criteria included those who consented to participate in the study. Students with history of medical illness including thyroid diseases, autoimmune disease, asthma, epilepsy and any psychiatric ailment were excluded. A structured questionnaire was designed to assess the demographic characteristics and symptoms of PMS if any experienced by the participants included in the study .Diagnosis of PMS in this study was made if the participant reported symptoms five days before menstrual cycle in last three menstrual cycles. At least one of the following affective symptoms including depression, irritability, angry outbursts, anxiety or social withdrawal and any one of somatic symptoms including headache, abdominal bloating, breast tenderness or extremities swelling. These symptoms must have relieved within 4 days of the onset of menses and did not reoccur till twelfth day of menses. (According to the diagnostic criteria of ACOG). ${ }^{2}$ The severity symptoms of PMS were marked by the participants on the behalf of their impact on their routine activity \& performance, ranking from mild, moderate to severe. Statistical analysis was carried out using SPSS software version 22. Percentage was calculated for descriptive variables. Chi-square test was applied to find the significant associations. Statistical significance was set at $\mathrm{P}<0.05$.

\section{RESULTS:}

PMS was diagnosed in 58 medical students of the 150 participants in the study, while 92 did not had PMS. The prevalence of PMS among the study participants was (39 $\%$ ), among them (79.31\%) showed mild form, (17.24\%) showed moderate degree and $(3.44 \%)$ were diagnosed with severe PMS. (Figure II). N=31( 20.66\%) participants were less than 20 years of age, $\mathrm{n}=58(38.66 \%)$ were between 20 22 years of age, and $n=61(40.66 \%)$ were between 23 to 25 years of age. The data was analyzed using the Chi-square test (p-value 0.650) and no statistical significance was found between age and the incidence of PMS ( Table-I). N=21(14\%) were studying in first year of MBBS, $n=4(19 \%)$ of whom were diagnosed to be suffering with PMS. $\mathrm{N}=29(19.3 \%)$ were in the second year of MBBS, $n=7(24.1 \%)$ of them had PMS. N=21( $18 \%$ ) were in the third year of MBBS with $\mathrm{n}=9(33.3 \%)$ of them being diagnosed with PMS . $\mathrm{N}=29$ ( $19.3 \%)$ were fourth year students with $n=14(48.2 \%)$ of them had PMS. Lastly among final year MBBS students $\mathrm{n}=44(29.33 \%)$ were enrolled in the study among them $\mathrm{n}=24$ ( $54.54 \%)$ being eventually diagnosed with Premenstrual Syndrome. The data was analyzed using chisquare test ( $p$-value $=0.016)$ and significant association was seen between the year of MBBS and the incidence of Premenstrual syndrome. Increase in frequency of PMS in female medical students was observed to be associated with progression of their academic years, with final year students having highest percentage.

Majority of them ( $\mathrm{n}=86,57.33 \%)$ had age of menarche between 10 to 13 years.

Among 150 participants, $48.66 \%$ revealed irregularcycles, in whom $28.76 \%$ were having PMS. While menstrual cycle was regular in $51.33 \%$ of participants. Regarding residence status, $\mathrm{n}=78(52 \%)$ participants were residing in hostel, $\mathrm{n}=38$ (48.71\%) of whom suffered from symptoms of PMS, compared to $n=72(48 \%)$ day scholars in whom only $n=20$ (27.77\%) were diagnosed with PMS.

Figure I: Percentage Of PMS Among Medical Students

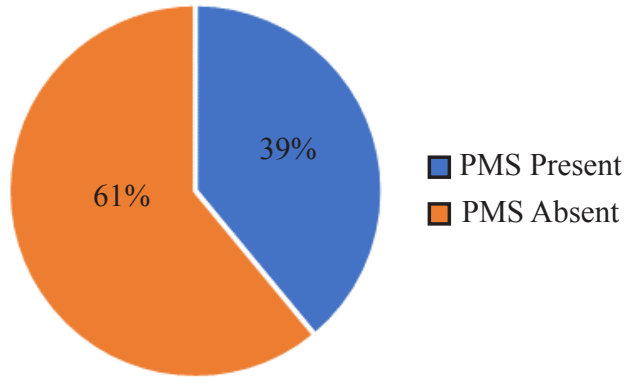

Figure II: Severity Of PMS Among Medical Students

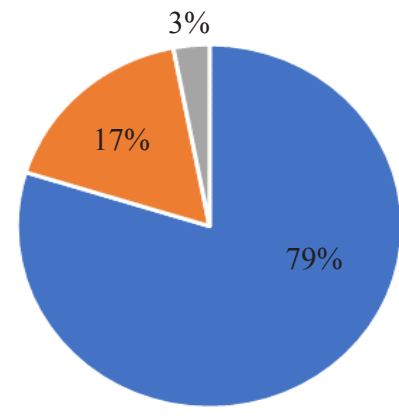

Mild PMS

Moderate PMS

Severe PMS 
Assessment Of Premenstrual Syndrome In Medical Students And Its Association With Progression Of Academic Years

Table 1: Demographics And Characteristics Of Students Enrolled.

\begin{tabular}{|c|c|c|c|c|}
\hline & $\begin{array}{c}\text { With PMS } \\
n=58\end{array}$ & $\begin{array}{c}\text { Without } \\
\text { PMS } \\
n=92\end{array}$ & $\begin{array}{c}\text { Total } \\
(100 \%)\end{array}$ & P-value \\
\hline$<20$ & $11(35.5 \%)$ & $20(64.5 \%)$ & 31 & \multirow{4}{*}{0.650} \\
\hline $20-22$ & $21(36.2 \%)$ & $37(63.7 \%)$ & 58 & \\
\hline $23-25$ & $26(42.6 \%)$ & $35(57.3 \%)$ & 61 & \\
\hline Total & $58(38.7 \%)$ & $92(61.3 \%)$ & $150(100 \%)$ & \\
\hline 1st year & $4(19 \%)$ & $17(81 \%)$ & 21 & \multirow{6}{*}{0.016} \\
\hline 2nd year & $7(24.1 \%)$ & $22(75.9 \%)$ & 29 & \\
\hline 3 rd year & $9(33.3 \%)$ & $18(66.6 \%)$ & 27 & \\
\hline 4 th year & $14(48.2 \%)$ & $15(51.8 \%)$ & 29 & \\
\hline Final year & $24(54.5 \%)$ & $20(45.5 \%)$ & 44 & \\
\hline Total & $58(38.7 \%)$ & $92(61.3 \%)$ & $150(100 \%)$ & \\
\hline $10-13$ years & $31(36 \%)$ & $55(64 \%)$ & 86 & \multirow{3}{*}{0.445} \\
\hline$>13$ years & $27(42.2 \%)$ & $37(57.8 \%)$ & 64 & \\
\hline Total & $58(38.7 \%)$ & $92(61.3 \%)$ & $150(100 \%)$ & \\
\hline Hostel & $38(48.7 \%)$ & $40(51.3 \%)$ & 78 & \multirow{3}{*}{0.008} \\
\hline Day Scholar & $20(27.8 \%)$ & $52(72.2 \%)$ & 72 & \\
\hline Total & $58(38.7 \%)$ & $92(61.3 \%)$ & $150(100 \%)$ & \\
\hline Nuclear & $40(43.5 \%)$ & $52(56.5 \%)$ & 92 & \multirow{3}{*}{0.127} \\
\hline Joint & $18(31 \%)$ & $40(69 \%)$ & 58 & \\
\hline Total & $58(38.7 \%)$ & $92(61.3 \%)$ & $150(100 \%)$ & \\
\hline Illiterate & $12(52.2 \%)$ & $11(47.8 \%)$ & 23 & \multirow{3}{*}{0.148} \\
\hline Literate & $46(36.2 \%)$ & $81(63.8 \%)$ & 127 & \\
\hline Total & $58(38.7 \%)$ & $92(61.3 \%)$ & $150(100 \%)$ & \\
\hline Housewife & $33(50.7 \%)$ & $32(49.2 \%)$ & 65 & \multirow{3}{*}{0.007} \\
\hline Working women & $25(29.4 \%)$ & $60(70.6 \%)$ & 85 & \\
\hline Total & $58(38.7 \%)$ & $92(61.3 \%)$ & $150(100 \%)$ & \\
\hline Regular & $37(48 \%)$ & $40(52 \%)$ & 77 & \multirow{3}{*}{0.015} \\
\hline Irregular & $21(28.8 \%)$ & $52(71.2 \%)$ & 73 & \\
\hline Total & $58(38.7 \%)$ & $92(61.3 \%)$ & $150(100 \%)$ & \\
\hline Present & $33(54 \%)$ & $28(46 \%)$ & \begin{tabular}{|l|}
61 \\
\end{tabular} & \multirow{3}{*}{0.001} \\
\hline Absent & $25(28 \%)$ & $64(72 \%)$ & 89 & \\
\hline Total & $58(38.7 \%)$ & $92(61.3 \%)$ & $150(100 \%)$ & \\
\hline
\end{tabular}

About $61.33 \%$ of girls came from nuclear families. Majority of the mothers of participants were literate $(84.66 \%)$, while only $15.33 \%$ of them were illiterates. Eighty five participants mothers were working women $(56.66 \%)$ by occupation, while sixty five $(43.33 \%)$ were house wives.

PMS was significantly more frequent in girls with family history of PMS ( $\mathrm{p}=0.001)$.

PMS was not found to be statistically associated with age, age of menarche, type of family, and education of mother.

\section{DISCUSSION:}

In the present study, the prevalence of PMS among the female medical students of United Medical and Dental College was $39 \%$. Similarly an Indian study conducted by Rumana AM et al, found a prevalencerate of $31.1 \%$ among medical students of Basaveshwara medical college, Chitradurga. ${ }^{14}$ Nearly similar prevalence of PMS was observed in Thai high school students, study conducted by Buddhabunyakan $\mathrm{N}$ et al. ${ }^{15}$

However a higher prevalence rate of $92.4 \%$ of PMS was present among female students of Army Medical College (NUST), Islamabad, in a study conducted by Rizwan hashim et al, ${ }^{16}$ Sarkar AP et al, and Pal et al, alsoreported high prevalent figures of $61.5 \%$ and $79.9 \%$ respectively. ${ }^{17,18}$ This difference could be due to the difference of prevalence in general community and the selective groups, age, bachelorhood, marital status, employment status, educational status etc.Among the study participants $79.31 \%$ showed mild form of PMS , 17.24\% showed moderate degree and $3.44 \%$ were diagnosed with severe PMS in current study. In a study conducted by Nusrat Nisar et al59.5\% had mild PMS, 29.2\% had moderate and 11.2\% had severePMS. ${ }^{9}$

While the frequency distribution of the PMS cases reported by Magdy Hassan Balaha et al, were as $45 \%$ mild, $32.6 \%$ moderate and $22.4 \%$ severe cases. ${ }^{19}$ Present study reports higher prevalence of PMS among 23-25 years old medical students compared to other age groups, but it was not statistically significant. Increase in frequency of PMS in female medical students was observed to be associated with progression of their academic years, with final year students having highest percentage then compared to other academic years. This might be due to higher level of stress due to tough and demanding final year medical studies. These findings were consistent with the study conducted previously by Rumana AM et al,. ${ }^{14}$ Magdy Hassan Balaha et al reported that PMS had a significant association with older age groups in medical students. ${ }^{19}$

In the current study, no association was found between age of menarche and development of premenstrual syndrome. These finding were consistent with study conducted by El -Defrawi $\mathrm{MH}$ et al, ${ }^{20}$ in contrast to it, Abu-Hashem $\mathrm{H}$, et al did found association between PMS and age at menarche. ${ }^{21}$

PMS was found to be more frequent among students residing in hostels in present study, this is in agreement with study conducted by Rumana AM,et al. ${ }^{14}$

Regarding educational status of mother and occupation of mother, no association was reported for educational status of mother but occupation of mother was found to be statistically significant in present study. However no such association was found by Magdy Hassan Balaha et al. ${ }^{19}$ In study conducted by Sarakar AP et al, PMS was not found to be statistically associated with education of mother, whereas occupation of mother was found to be statistically significant.$^{17}$

History of regular menstrual cycle was found to be predisposing factor for development of premenstrual syndrome, in the current study. This was in agreement with some previous studies. ${ }^{22}$ On the contrary, Sarkar AP etal, did not reported any association between PMS and regularity of menstrual cycle.$^{17}$ 
Finally, the family history of PMS was found to be statistically significant associated risk factor in our study; this is in line with NFarahmand $\mathrm{M}$ et al. and Rasheed $\mathrm{P}$ et al. ${ }^{23,24}$

In the light of this study, further large-scale studies would be recommended to evaluate the prevalence of PMS in community, impact of PMS on quality of life and effective interventions for alleviating PMS among general community and high-risk population like medical students. Counseling and health services should be made accessible and available. It is recommend that health education, counseling and medical services to be provided at medical college campuses for female students. Adequate means should be taken to promote a healthy and stress free environment in medical colleges, especially in hostels. Comfortable conditions should be provided with the availibity of counselors to avoid the symptoms of PMS and its consequences.

\section{CONCLUSION:}

Premenstrual syndrome is a prevalent health issue in medical students, increasing year to year during their studies, which may unfavorably have affects on their quality of life and overall performance.

\section{REFRENCES:}

1. World Health Organization. International Statistical Classification of Diseases and Related Health Problems (ICD10) [Internet]. Geneva: World Health Organization; 2010.

2. American College of Obstetrics and Gynecology: ACOG practice bulletin: premenstrual syndrome. Washington DC: ACOG, 2000:15.

3. ACOG practice bulletin: premenstrual syndrome. Int J Gynecol Obstet 2001;73:183-91.

4. American Psychiatric Association. Diagnostic and Statistical Manual of Mental Disorders. 5th ed. Washington, DC: APA Press; 2012:465-475.

5. Ismail KMK, Crome I, O'Brien PM. PsychologicalDisorders in Obstetrics and Gynaecology forMRCOG and beyond. London: RCOG Press;2006. p. 29-40.

6. Pearlstein T. Prevalence, impact on morbidity, and disease burden. In: O'Brien PM, Rapkin AJ, Schmidt PJ, editors. The Premenstrual Syndromes: PMS and PMDD. Boca Raton, FL, USA: CRC Press; 2007; 37-47.

7. Borenstein JE, Dean BB, Endicott J, Wong J, Brown C, Dickerson V, et al. Health and economic impact of the premenstrual syndrome. J Reprod Med 2003; 48:515-24.

8. Elizabeth R. Bertone-Johnson, Susan E. Hankinson, Susan R. Johnson, and JoAnn E. Manson. Cigarette Smoking and the Development of Premenstrual Syndrome. Am J Epidemiol 2008;168:938-945.

9. Nisar N, Zehra N, Haider G, Munir AA, Sohoo NA.Frequency, intensity and impact of Premenstrual Syndrome in medical students. J Coll Physicians Surg Pak 2008;18:481-4.
10. Yonkers KA, O’Brien PM, Eriksson E. Premenstrual syndrome. Lancet 2008;371:1200-10.

11. Christine P west. Premenstrual syndrome. In: Luesley DM, Baker PN, editors. Obstetrics and gynaecology: An evidence based text book for MRCOG. London: Edward Arnold; 2010. p.591-97.

12. P.M.Shaughn O Brien. Premenstrual Syndrome. In: Edmonds DK, editor. Dewhursts text book of obstetrics and gynaecology. USA: Blackwell ; 2007. p.544-52.

13. Samadi Z, Taghian F, and Valiani M. The effects of 8 weeks of regular aerobic exercise on the symptoms of premenstrual syndrome in non-athlete girls. Iran J Nurs Midwifery Res. 2013 Jan-Feb; 18(1): 14-19.

14. Rumana AM, Sudharani M, Kallupurackal SJX, Ramya V, Nagendra GMR, Suryakantha AH. Prevalence of Premenstrual Syndrome among Medical Students. Natl J Community Med 2017; 8(6):292-294.

15. Buddhabunyakan N, Kaewrudee S, Chongsomchai C, Soontrapa S, Somboonporn W, Sothornwit J. Premenstrual syndrome (PMS) among high school students .; 501-505.

16. Hashim R, Ayyub A, Hameed S, Qamar K, Ali S, Raza G. Premenstrual Syndrome; Messes with my academic performance.Pak Armed Forces Med J 2014; 64 (2): 199-203.

17. Sarkar AP, Mandal R, Ghorai S. Premenstrual syndrome among adolescent girl students in a rural school of West Bengal, India. Int J Med Sci Public Health 2016;5:408-411.

18. Pal S, Dennerstein L, Lehert P. Premenstrual symptoms in Pakistani women and their effect on activities of daily life. JPMA 2011; 61: 763.

19. Balaha MH, Mostafa Abd El Monem Amr, Mohammed Saleh Al Moghannum, Nouria Saab Al Muhaidab.. The phenomenology of premenstrual syndrome in female medical students: a cross sectional study. Pan African Medical Journal. 2010; 5:4.

20. El -Defrawi MH, Lotfi G, Mahfouz R. Late luteal phase dysphoric disorder, Do we need another psychiatric category? Egyptian Journal of Psychiatry. 1990;13:205-212.

21. Abu-Hashem H, Amr M, Allam AF, Yousef H, Nemar A. Premenstrual syndrome (PMS) in a sample of Egyptian adolescents. J Egy Soc Obstet Gynecol. 2006;32:417-18

22. Mishell DR Jr. Premenstrual disorders: Epidemiology and disease burden. Am J Manag Care. 2005 Dec;11(16 Suppl):S473-9.

23. Farahmand M, Ramezani Tehrani F, Khalili D, Amin G, Negarandeh R. Factors associated with the severity of premenstrual syndrome among Iranian college students. J Obstet Gynaecol Res. 2017 Nov;43(11):1726-1731.

24. Rasheed P, Al sowielem L. Prevalence and predictors of premenstrual syndrome among college aged women in Saudi Arabia . An Saudi Med 2003,23; 381-387. 